\title{
STRESS DISTRIBUTION IN FRONT OF THE CRACK - ANALYTICAL SOLUTIONS VS. NUMERICAL. CAN THE DIFFERENCES BE MINIMIZED?
}

\author{
Andrzej Neimitz, Sebastian Lipiec
}

Kielce University of Technology, Faculty of Mechatronics and Mechanical Engineering, Kielce, Poland

e-mail: neimitz@tu.kielce.pl; s.lipiec@tu.kielce.pl

It is shown that it is possible to obtain such parameters as $\alpha$ and $Q$, which, when used in the analytical formulae proposed by O'Dowd and Shih, can lead to stress distributions similar to those obtained numerically. The numerical solution obtained after calibration of the stress-strain uniaxial curve and assuming large strains is expected to be close to the "real" stress distribution. Thus, the analytical solution after correction is also close to the "real" stress distribution. These new values of $\alpha$ and $Q$ can now be used in fracture criteria proposed within the scope of classical nonlinear fracture mechanics.

Keywords: stress distribution in front of crack, HRR, constitutive equation calibration

\section{Introduction - classical fracture mechanics and the stress distribution in front of the crack}

Classical elastic-plastic fracture mechanics was born in 1968 with the papers by Hutchinson (1968) and Rice and Rosengren (1968). The Dugdale model (1960) had previously introduced the plastic zone in front of the crack as a strip-yield zone under the strong assumptions of a plane stress state and the Tresca yield condition only. The Hutchinson-Rice-Rosengren (HRR) solution was also derived under the strong simplifying assumptions of a plane strain state, the Ramberg-Osgood (RO) constitutive relationship and small strains. In the HRR solution, the plastic stress intensity factor was replaced (McClintock, 1971) by Rice's $J$-integral (Rice, 1968) (see also Cherepanov, 1967) representing the amplitude of the singular field in front of the crack, Eq. (1.1), and this theory has dominated the field of nonlinear fracture theory

$$
\left(\sigma_{i j}\right)_{H R R}=\sigma_{0}\left(\frac{J}{\alpha \varepsilon_{0} \sigma_{0} I_{n} r}\right)^{\frac{1}{1+n}} \widetilde{\sigma}_{i j}(n, \theta)+\ldots
$$

where $J$ is the $J$-integral, $\sigma_{0}$ is the yield strength, $\varepsilon_{0}=\sigma_{0} / E, E$ is Young's modulus, $n$ and $\alpha$ are the power exponent and coefficient in the RO constitutive relation, respectively, $I_{n}$ is a function that depends on $n$, and this function can be found, e.g., in (Neimitz et al., computer program), $\widetilde{\sigma}_{i j}(\theta, n)$ can also be found for selected $n$ in (Neimitz et al., computer program) for an arbitrary material for the plane stress, plane strain and three-dimensional cases, and $r$ and $\theta$ are the coordinates of the polar coordinate system located at the crack tip.

The fracture criterion using the $J$-integral is actually conservative, and the second term, the $Q$-stress, which replaces all neglected terms in the asymptotic expansion for the stress field, was introduced by O'Dowd and Shih (OS) (1991)

$$
\sigma_{i j}=\left(\sigma_{i j}\right)_{H R R}+Q \sigma_{0} \widehat{\sigma}_{i j}(n, \theta)
$$

where $Q$, computed according to O'Dowd and Shih (1991), represents the difference between the analytical $\left(\sigma_{\theta \theta}\right)_{H R R}$ and numerical results $\left(\sigma_{\theta \theta}\right)_{F E M}$ at the fixed normalized distance as shown as 


$$
Q=\frac{\left(\sigma_{\theta \theta}\right)_{F E M}-\left(\sigma_{\theta \theta}\right)_{H R R}}{\sigma_{0}} \quad \text { at } \quad \theta=0 \quad \gamma=\frac{r \sigma_{0}}{J}=2
$$

The reference value can be obtained as the HRR field $\left(\sigma_{\theta \theta}\right)_{H R R}$, Eq. (1.1), or as a numerical result computed on the assumption of small-scale yielding (the boundary layer approach). This problem was also discussed in detail by O'Dowd (1995). Equations (1.1) and (1.2) are derived on the assumption of a plane strain.

This $Q$-stress was introduced to reduce the conservatism of the critical moment assessment (Koçak et al., 2008; O'Dowd, 1995; Ainsworth and O'Dowd, 1995; Neimitz et al., 2007). Almost at the same time as the OS paper was published (O'Dowd and Shih, 1991) (two years later), Yang, Chao and Sutton (YCS) (Yang et al., 1993) derived a formula for the stress distribution in front of the crack containing three terms. Both the OS and YCS formulae introduced an important correction to the stress distribution in front of the crack; however, those approaches still suffered from the strong assumptions of a plane strain and small strains. The $Q$-stress cancels out the difference between the numerical and analytical solutions in the case of the plane strain assumption. The $Q$-stress is equal to zero for the plane stress; thus, this quantity must change along the crack front, from the specimen axis (the state almost dominated by plane strain) to the specimen surface (the state dominated by plane stress) when the 3D situation would be considered. Using a measure of the stress triaxiality that could be Guo's $T_{z}$ parameter, the stress distribution was corrected to introduce the specimen thickness effect on the stress level (Guo, 1997; Neimitz and Graba, 2008; Neimitz and Dzioba, 2015; Xiang and Guo, 2013)

$$
\sigma_{i j}=\sigma_{0}\left(\frac{J^{f a r}}{\alpha \sigma_{0} \varepsilon_{0} I_{n}\left(T_{z}, n\right) r}\right)^{\frac{1}{1+n}} \widetilde{\sigma}_{i j}\left(\theta, n, T_{z}\right)
$$

where $T_{z}$ is defined as

$$
T_{z}=\frac{\sigma_{33}}{\sigma_{11}+\sigma_{22}}
$$

The functions $\tilde{\sigma}_{i j}\left(\theta, n, T_{z}\right)$ and $I_{n}(n, T z)$ can be found using a computer program (Neimitz et al.). Also the assumption of small strains was kept in this case.

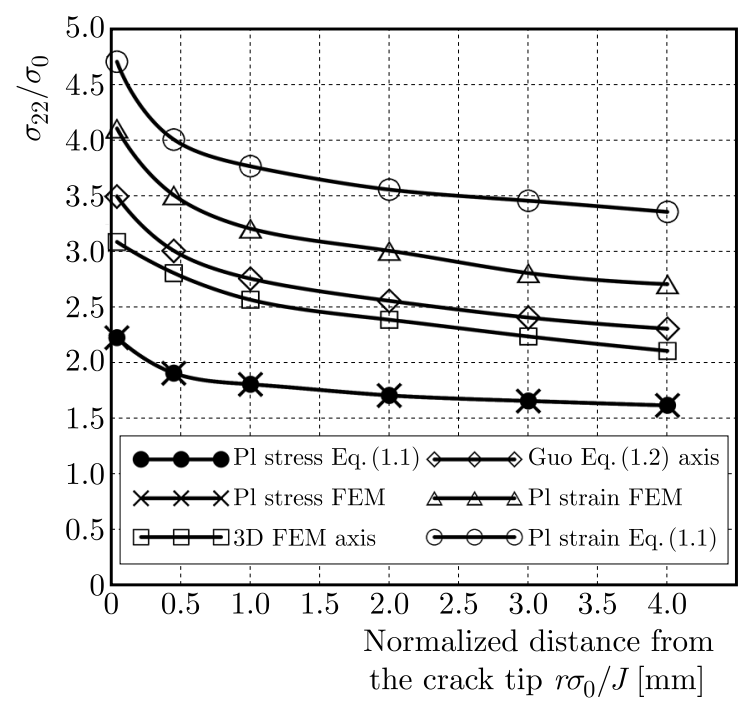

Fig. 1. Stress - distance from the crack front curves following numerical and analytical Eqs. (1.1) and (1.4) computations (Neimitz and Graba, 2008)

Figure 1 demonstrates the strong influence of the out-of-plane constraint when the assumption of plane strain is neglected. The results obtained using OS, YCS or Guo's $T_{z}$ parameters 
are generally compared with the finite element method results. However, in the finite element method, it remains the case that small strains and the RO constitutive equations are still assumed.

The HRR model requires two parameters from the RO constitutive equation $\left(\varepsilon_{11}=\right.$ $\alpha\left(\sigma_{11} / \sigma_{0}\right)^{n}$, uniaxial version), that is, $\alpha$ and $n$. The approach used to determine these material parameters is not unique using experimental data and the engineering stress-strain relationship; this problem was discussed in detail by O'Dowd (1995).

\section{Numerical computation of the stress field in front of the crack}

Numerical computations of the stress field in front of the crack require a constitutive equation, which can be introduced either as the RO formula to compare the results with analytical results or can be a stress-strain curve obtained in the uniaxial test if one wishes to obtain the results possibly close to the "real" values. To make the model as close as possible to the real environment in front of the crack in an elastic-plastic material, finite strains must be assumed, and 3D geometry must be used. Moreover, to be as close as possible to the real environment in front of the crack, the true stress-logarithmic strains should be calibrated (Bai and Wierzbicki, 2008). The calibration should take into account the triaxiality parameter, $\eta=\sigma_{m} / \sigma_{e}$ where $\sigma_{m}$ and $\sigma_{e}$ are the first stress tensor invariant and the effective stress, respectively; and the Lode angle/parameter. The calibration influences the stress distribution in front of the crack as shown in Fig. 2. Note that after the calibration, which takes into account material softening at the last stage of loading (Bai and Wierzbicki, 2008; Neimitz et al., 2018), the results are acceptable from the physical point of view; the curves go down towards the crack tip before the stress maximum is reached. It is not particularly important what specimen shape is used for the calibration as long as the stress triaxiality is suitably high. The stress maximum after calibration (material N, temp. $+20^{\circ} \mathrm{C}$, Table 1 ) is lower by $2.6 \%$ than the results obtained by computation without calibration. The stress maximum lies in the range from $1291 \mathrm{MPa}$ to $1297 \mathrm{MPa}$ for the results of computations performed using calibrated stress-strain curves. The differences between the distances of the stress maximum from the crack tip are within the range of $4 \mu \mathrm{m}$.

An exemplary result of such calibration according to the procedure presented in (Neimitz et al., 2018) is shown in Fig. 2.

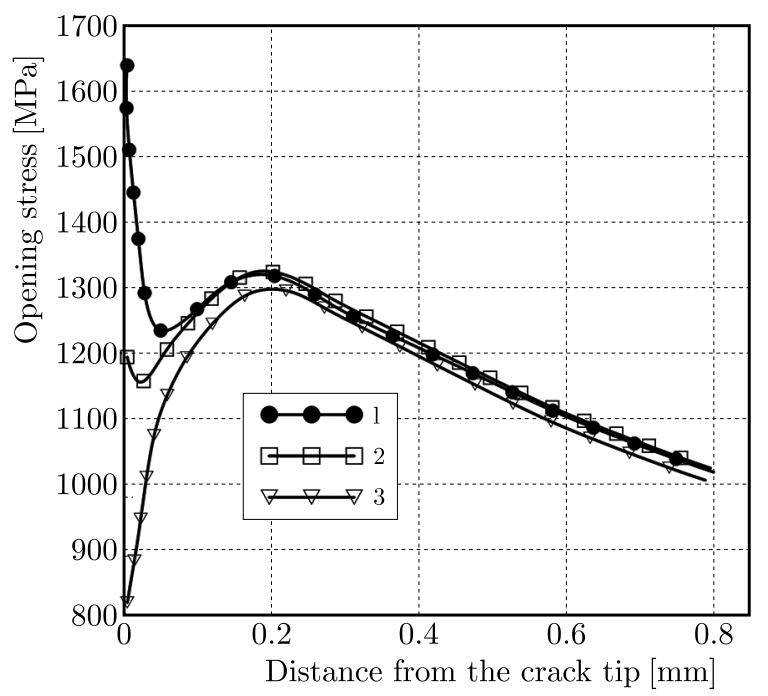

Fig. 2. Stress distribution in front of the crack: curve 1 - true stress-log.strain curve extrapolated as a linear function, no calibration; curve 2 - true stress-log.strain curve extrapolated as a power function, no calibration; curve 3 - after calibration including material softening (material $\mathrm{N}$, temp. $+20^{\circ} \mathrm{C}$ 
The curves in Fig. 2 were obtained from a single-edge-notch-bend (SEN(B)) specimen. Thickness of the specimen was $B=12 \mathrm{~mm}$, and width $W=24 \mathrm{~mm}$. These specimen dimensions satisfy the requirements of the plane strain. One half of the specimen thickness was divided into 11 layers. The distributions shown in Fig. 2 were computed for the central layer. Large strains were assumed, and $J_{2}$ plasticity was incorporated. Linear, hexagonal C3D8 elements (ABAQUS) with full integration were used. The crack tip was blunted by a $12 \mu \mathrm{m}$ radius. The size of the finite elements increased with increasing distance from the crack tip. The size of the smallest element was $27 \mu \mathrm{m}$. Thickness of the layers through the thickness decreased towards the specimen external surface. The thinnest layer was $0.27 \mathrm{~mm}$.

The mechanical properties of the materials tested in the research programs are listed in Table 2 .

Table 2. Mechanical properties of the tested materials

\begin{tabular}{|c|c|c|c|c|c|c|c|c|}
\hline & $\begin{array}{c}\text { Heat } \\
\text { treatment }\end{array}$ & Microstructure & $\begin{array}{c}\text { Temp. } \\
{\left[{ }^{\circ} \mathrm{C}\right]}\end{array}$ & $\begin{array}{c}E \\
{[\mathrm{GPa}]}\end{array}$ & $\begin{array}{c}R_{e L} \\
{[\mathrm{MPa}]}\end{array}$ & $\begin{array}{c}R_{e H} \\
{[\mathrm{MPa}]}\end{array}$ & $\begin{array}{c}R_{m} \\
{[\mathrm{MPa}]} \\
\end{array}$ & $n$ \\
\hline \multirow{2}{*}{$\begin{array}{c}\text { S355JR } \\
\text { steel, } \\
\text { symbol NW }\end{array}$} & \multirow{2}{*}{$\begin{array}{c}\text { Normalized } \\
\text { and annealed } \\
\left(600^{\circ} \mathrm{C}, 150 \mathrm{~h}\right)\end{array}$} & \multirow{2}{*}{$\begin{array}{c}\text { Ferrite } \\
\text { containing } \\
\text { spheroidized } \\
\text { carbide particles }\end{array}$} & +20 & 210 & 382 & 368 & 470 & 8.9 \\
\hline & & & -50 & 212 & 390 & 396 & 526 & 7.1 \\
\hline symbol N & $\begin{array}{c}\text { Normalized } \\
\text { at } 950^{\circ} \mathrm{C}\end{array}$ & Ferrite-pearlite & +20 & 197 & 367 & 375 & 496 & 7.9 \\
\hline
\end{tabular}

The results presented in Figs. 1 and 2 show different pictures of the stress distributions in front of the crack for the same material, specimen geometry and external loading. The researcher faces an important problem. If one wishes to use the classical engineering approach and the fracture criterion based on the $J$-integral, the small strain, plane strain and RO constitutive equation must be used. The more advanced approach using the OS or YCS solutions can also be used based on certain theories published previously (Koçak et al., 2008; O'Dowd, 1995; Ainsworth and O'Dowd, 1995; Neimitz et al., 2007; Guo, 1997; Neimitz and Graba, 2008; Neimitz and Dzioba, 2015; Xiang and Guo, 2013). However, when using these approaches, one knows that the stress distribution in front of the crack is not correctly computed for two reasons: the small strain assumption and the RO constitutive equation, which in most cases is not uniquely determined. The question arises: can one minimize the differences between the stress distributions computed analytically using Eq. (1.2) and numerically, computed in such a way that the result is close to the "real" distribution? This problem is discussed in the next Section.

\section{Analytical solutions vs. numerical solutions}

It is assumed that the numerical solution is based on the following conditions:

a) The real stress-strain curve is obtained in the uniaxial tensile test and converted to the real stress-logarithmic strain and properly calibrated.

b) Finite strains and J2 theory of plasticity are incorporated.

c) A 3D model of the specimen is employed.

These conditions provide results that are the closest to the real stress distribution in front of the crack. In a real situation (i.e., the $3 \mathrm{D}$ case), the pure plane strain condition $\left(T_{z}=0.5\right)$ is not often met close to the crack front. The situation close to the plane strain is observed in the central part of the specimens tested. The $T_{z}$ parameter is greater than 0.4 in the domain from 0 to $0.45 \mathrm{~mm}$ from the crack front for the specimens tested in the present research program. All 
tested specimens satisfy the requirements of the plane strain. Thus, the stress distribution in the central part of the specimen will be considered in this paper, and this stress distribution is considered the reference result and is used to correct the stress distribution obtained using Eqs. (1.1) and (1.2) (O'Dowd and Shih, 1991).

In the first step on the way to force the stress distribution in front of the crack, as computed using Eq. (1.2), to be as close as possible to the stress distribution computed using the finite element method, the constitutive equation is calibrated. The modified Bai-Wierzbicki (2008) procedure is applied and the results are published in (Neimitz et al., 2018). Calibration was performed using four different specimen geometries characterized by a high triaxiality factor $\eta$ and a wide range of the Lode parameter values. In addition, the softening of material due to the massive voids growth and coalescence was introduced. In the further analysis, the calibration procedure including material softening due to the void growth and coalescence was implemented. Computations were performed at the presumed onset of the crack growth. The stress distributions were recorded for the central layers of the specimens (selected curves are shown in Fig. 2). For this layer, the $J$-integral was also computed.

In the second step, three points are selected along the curve representing the crack opening stress tensor component $\sigma_{22}$. An exemplary stress distribution is shown in Fig. 3.

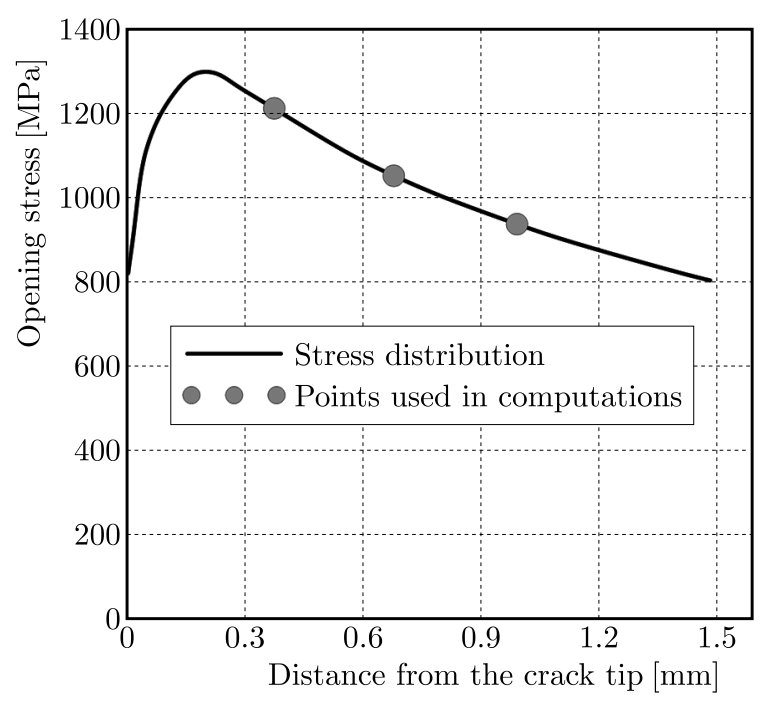

Fig. 3. Stress distribution in front of the crack computed numerically, material N, temp. $+20^{\circ} \mathrm{C}$

The curve in Fig. 3 was recorded for material N (temp. $+20^{\circ} \mathrm{C}$ ). Each of the selected points has two coordinates $\sigma_{22}$ and $r$. These coordinates were introduced into Eq. (1.2), and three equations were obtained with three unknowns: $\alpha, n$ and $Q$. Notably, no unique solution of this set of equations exists in most cases. Thus, in the third step, it was assumed that the curve passing through the selected points along the curve, as in Fig. 3, is the power function, as in Eq. (1.1), and that the exponent $n$ is the same as obtained in the stress-strain relation in the uniaxial tensile test and used in the HRR formula, Eq. (1.1). The curve in Fig. 3 was obtained using finite elements in conjunction with calibrated constitutive equations, starting from the true stress-logarithmic strain curve. It is also assumed that the $Q$-stress in Eq. (1.2) is not constant (in fact it is not; see the OS paper (O'Dowd and Shih, 1991)), but that the variations are not strong. To ensure agreement with the OS postulate, the reference value of the $Q$-stress should be measured at the normalized distance from the crack front $\gamma=r \sigma_{0} / J=2$. Thus, the formula used to determine the parameters in modified Eq. (1.2) is as follows

$$
\sigma_{22}=\sigma_{0}\left(\frac{J}{\sigma_{0} \varepsilon_{0} I_{n} \alpha r}\right)^{\frac{1}{1+n}} \widetilde{\sigma}_{22}(n, \theta)+\left(Q_{\gamma=2}+\Delta Q\right) \sigma_{0}
$$


or using the normalized distance from the crack front $\gamma=r \sigma_{0} / J$

$$
\sigma_{22}=\sigma_{0}\left(\frac{E}{\sigma_{0} I_{n} \alpha \gamma}\right)^{\frac{1}{1+n}} \widetilde{\sigma}_{22}(n, \theta)+\left[Q_{\gamma=2}+\beta(\gamma-2)\right] \sigma_{0}
$$

In Eq. (3.2), $\Delta Q$ is replaced by $\beta(\gamma-2)$, assuming a linear relationship. Thus, Eq. (3.2) contains three unknowns: $\alpha, \beta$ and $Q_{\gamma=2}$. Now selecting three points along the curve as in Fig. 3, a set of three algebraic equations with three unknowns can be obtained, and this set of equations has a unique solution. The computational results are shown below.

(a)

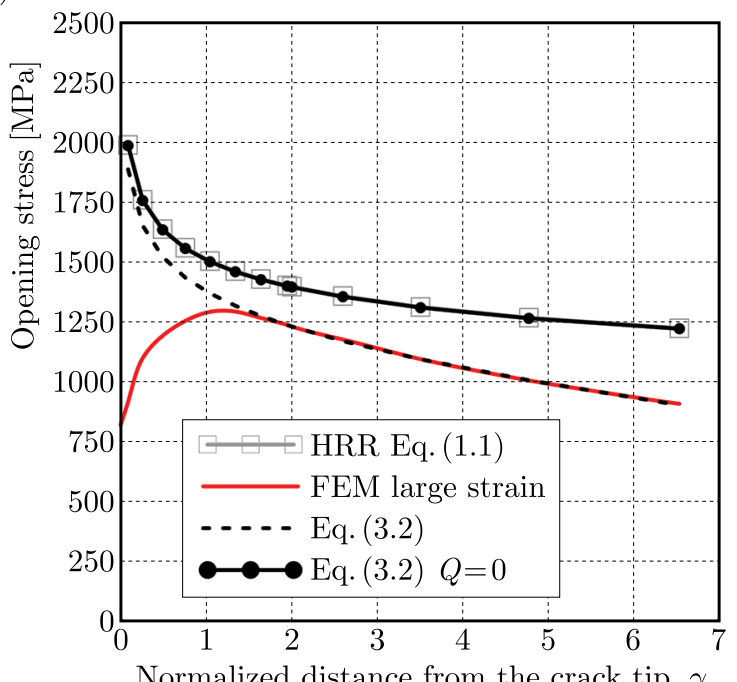

(b)

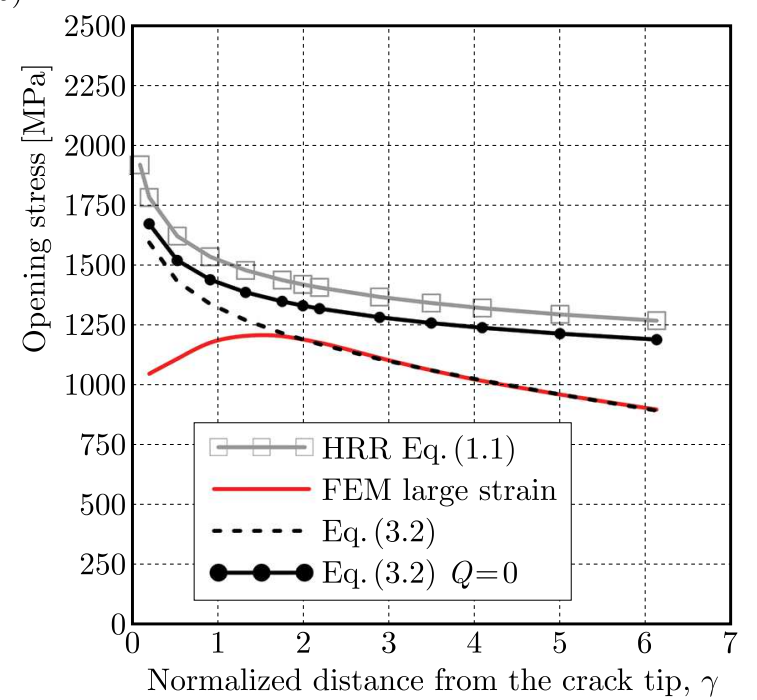

(c)

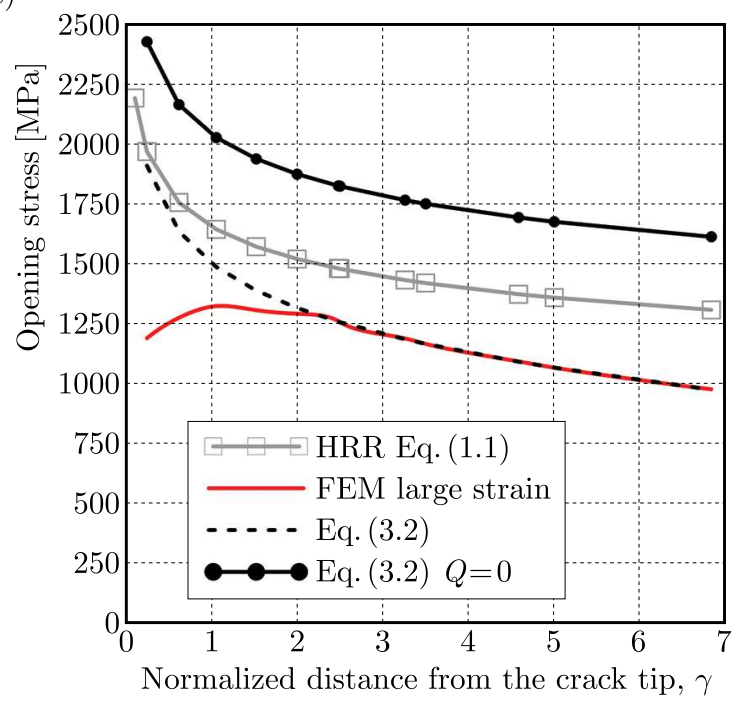

Fig. 4. Stress distributions in front of the crack, computed numerically, using Eq. (1.1), using Eq. (3.2) and Eq. (3.2) for $Q=0$ : (a) material N, temp. $+20^{\circ} \mathrm{C}$, (b) material $\mathrm{NW}$, temp. $+20^{\circ} \mathrm{C}$,

(c) material NW, temp. $-50^{\circ} \mathrm{C}$

The HRR curves obtained using Eq. (1.1) were drawn with the power exponent $n$ listed in Table 1 and $\alpha=1$ in the plastic region and a linear relation in the elastic region, according to the suggestions by O'Dowd (1995) as an option well representing both the elastic and plastic behaviour of the material in finite element computations. The quantities $I_{n}$ and $\widetilde{\sigma}_{22}(n, \theta)$ were found using a computer program (Neimitz et al.). Table 2 presents the numerical results and the $J$-integral, which was identical in computing all curves for each material. The computed values 
of $\alpha, \beta$ and $Q_{\gamma=2}$ are also listed in Table 3. The first term in Eqs. (3.1) and (3.2) is identical to Eq. (1.1), except the constant $\alpha$. The second term in Eqs. (3.1) and (3.2), the $Q$ term, is different than in Eq. (1.2) and it is defined as

$$
Q=\frac{\left(\sigma_{22}\right)_{F E M} \_L S-\left(\sigma_{22}\right)_{H R R \_} \alpha}{\sigma_{0}}
$$

where $\left(\sigma_{22}\right)_{F E M_{-} L S}$ is the stress distribution computed numerically using the option of large strains and calibrated constitutive equations. It is so called the reference stress distribution and replaces the term $\left(\sigma_{22}\right)_{F E M}$ in Eq. (1.3). The term $\left(\sigma_{22}\right)_{H R R_{-} \alpha}$ is identical to Eq. (1.1), except the constant $\alpha$ which now is computed, not assumed to be equal to 1 .

Table 3. Parameters obtained and used in computations

\begin{tabular}{|c|c|c|c|}
\hline & $\begin{array}{c}\text { Material N, } \\
\text { temp. }+20^{\circ} \mathrm{C}\end{array}$ & $\begin{array}{c}\text { Material NW, } \\
\text { temp. }+20^{\circ} \mathrm{C}\end{array}$ & $\begin{array}{c}\text { Material NW, } \\
\text { temp. }-50^{\circ} \mathrm{C}\end{array}$ \\
\hline \hline$n$ & 7.9 & 8.93 & 7.19 \\
\hline$I_{n}$ & 4.68 & 4.61 & 4.75 \\
\hline$\widetilde{\sigma}_{22}(n, \theta)$ & 2.41 & 2.46 & 2.38 \\
\hline$\alpha$ & 1.016 & 1.98 & 0.18 \\
\hline$\beta$ & -0.092 & -0.1 & -0.037 \\
\hline$Q_{\gamma=2}$ & -0.448 & -0.328 & -153 \\
\hline$\gamma_{1}, \gamma_{2}, \gamma_{3}$ & $2,3.5,5$ & $2,3.5,5$ & $2.5,3.5,5$ \\
\hline$J[\mathrm{kN} / \mathrm{mm}]$ & 60.67 & 42.66 & 58.65 \\
\hline$\sigma_{0}[\mathrm{MPa}]$ & 367.4 & 382 & 390 \\
\hline
\end{tabular}

\section{Concluding remarks}

It is shown in Section 3 that it is possible to obtain such parameters as $\alpha$ and $Q$, which, when used in the analytical formulae, Eqs. (1.1) and (1.2), can lead to stress distributions similar to those obtained numerically (except for the region directly at the crack front). We expect that the numerical solution obtained after calibration of the stress-strain uniaxial curve and assuming large strains is close to the "real" stress distribution. Thus, after corrections, the analytically obtained stress distribution is also close to the "real" stress distribution. The third parameter $\beta$ used in the stress distribution adjustment, makes the numerical and analytical results almost identical over the long distance ahead of the crack front.

Numerical results obtained after uniaxial stress-strain curve calibration are used in the so called local approach to fracture mechanics (Neimitz et al., 2018; O'Dowd, 1995; Shery et al., 205). Analytical HRR solution (Hutchinson, 1968; Rice and Rosengren, 1968; Dugdale, 1971; McClintock, 1971; Rice, 1968; Cherepanov, 1967) and later extensions of this theory (O'Dowd and Shih, 1991; Koçak et al., 2008; O'Dowd, 1995; Ainsworth and O'Dowd, 1995; Neimitz et al., 2007; Yang et al., 1993) are used in classical "engineering" fracture mechanics. Conservatism of fracture prediction following from the criterion

$$
J_{I}=J_{I C}
$$

can be reduced replacing $J_{I C}$ by $J_{I C_{-} Q}$ where the $J_{I C_{-} Q}$ is the plane strain critical $J$ value which is computed using the $Q$ stress according to one of theories:

- Xiang and Guo (2013)

$$
J_{I c_{-} Q}=J_{I C}\left(1-\frac{Q}{\sigma_{C} / \sigma_{0}}\right)^{\frac{n+1}{2}}
$$


- Neimitz et al. (2007)

$$
J_{I C_{-} Q}=J_{I C}\left(1-\frac{Q}{\sigma_{22}^{\max } / \sigma_{0}}\right)^{1+n}
$$

— Neimitz and Dzioba (2015)

$$
J_{I C_{-} Q}=J_{I C}\left[1+b(-Q)^{k}\right]
$$

where $\sigma_{C}$ is the critical stress to be found experimentally, $\sigma_{22}^{\max }$ is the maximum value of the crack opening stress computed numerically using the option of large strains (see Fig. 4), $b, k$ are constants which can be found using the procedure shown in (O'Dowd, 1995; Sherry et al., 2005a,b) or selected data in (Koçak et al., 2008). Equations (4.2)-(4.4) can still be used with the $Q_{\gamma=2}$ values computed according to the procedure shown in this paper, and this value together with $\alpha$ and $\beta$ makes analytical (engineering) and numerical (close to the real) stress distributions close to each other.

\section{Acknowledgements}

This research was performed with financial support from the Polish National Center of Science (NCN), grant No. UMO-2014/15/B/ST8/00205.

\section{References}

1. Ainsworth R.A., O'Dowd N.P., 1995, Constraint in the failure assessment diagram approach for fracture assessment, ASME Journal of Pressure Vessels Technology, 117, 260-267

2. BAi Y., WierzBicki T., 2008, A new model plasticity and fracture with pressure and Lode dependence, International Journal of Plasticity, 24, 1071-1096

3. Cherepanov G.P., 1967, O racprostranenii treshchin v sploshnoj srede, Prikladnaya Matematika i Mekhanika, PMM, 31, 3, 476-488

4. Dugdale D.S., 1960, Yielding of steel sheets containing slits, Journal of the Mechanics and Physics of Solids, 8, 100-104

5. Guo W., 1993, Elastoplastic three dimensional crack border field - I. Singular structure of the field, Engineering Fracture Mechanics, 46, 93-104

6. Hutchinson J.W., 1968, Singular behaviour at the end of a tensile crack in a hardening material, Journal of the Mechanics and Physics of Solids, 16, 13-31

7. Koçak M., Webster S., Janosch J.J., Ainsworth R.A., Koers R., edit., 2008, Fitnet: Fitness-for-Service. Fracture-Fatigue-Creep-Corrosion, GKSS Research Centre Geesthacht, ISBN 978-3-940923-00-4

8. McClintock F.A., 1971, Plasticity aspects of fracture, [In:] Fracture: an Advanced Treatise, H. Liebowitz (Edit.), Academic Press, New York and London, 3, 47-225

9. Neimitz A., Dzioba I., 2015, The influence of the out-of-plane and in-plane constraint on fracture toughness of high strength steel in the ductile to brittle transition temperature range, Engineering Fracture Mechanics, 147, 431-448

10. Neimitz A., GaŁkiewicz J., Dzioba I., 2018, Calibration of constitutive equations under conditions of large strains and stress triaxiality, Archives of Civil and Mechanical Engineering, 18, 1123-1135

11. Neimitz A., GaŁkiewicz J., Graba M., Computer program: Name: HRR_par program: Internet address: http://fracture.tu.kielce.pl/index.php?pokaz=hrr 
12. Neimitz A., Graba M., 2008, Analytical-numerical hybrid method to determine the stress field in front of the crack in 3D elastic-plastic structural elements, Proceedings of 17th European Conference on Fracture - Multilevel Approach to Fracture of Materials, Components and Structures, Brno, Czech Republic, article on CD, abstract - book of abstracts, p. 85

13. Neimitz A., Graba M., GaŁkiewicz J., 2007, An alternative formulation of the Ritchie-Knott-Rice local fracture criterion, Engineering Fracture Mechanics, 74, 8, 1308-1322

14. O'Dowd N.P., 1995, Applications of two parameter approaches in elastic-plastic fracture mechanics, Engineering Fracture Mechanics, 52, 3, 445-465

15. O’Dowd N.P., Sнiн C.F., 1991, Family of crack-tip fields characterized by a triaxiality parameter - I. Structure of fields, Journal of the Mechanics and Physics of Solids, 39, 8, 989-1015

16. RiCE J.R., 1968, A path independent integral and the approximate analysis of strain concentration by notches and cracks, Journal of Applied Mechanics, 35, 379-386

17. Rice J.R., Rosengren G.F., 1968, Plane strain deformation near a crack tip in a power-law hardening material, Journal of the Mechanics and Physics of Solids, 16, 1-12

18. Sherry A.H., Hooton D.G., Beardsmore D.W., Lidbury D.P.G., 2005a, Material constraint parameters for the assessment of shallow defects in structural components - Part II: Constraint based assessment of shallow cracks, Engineering Fracture Mechanics, 72, 2396-2415

19. Sherry A.H., Wilkes M.A., Beardsmore D.W., Lidbury D.P.G., 2005b, Material constraint parameters for the assessment of shallow defects in structural componenets - Part I: Parameter solutions, Engineering Fracture Mechanics, 72, 2373-2395

20. Xiang M., Guo W., 2013, Formulation of the stress fields in power law solids ahead of threedimensional tensile cracks, International Journal of Solids and Structures, 50, 3067-3088

21. Yang S., Chao Y.J., Sutton M.A., 1993, Higher order asymptotic crack tip in a power-law hardening material, Engineering Fracture Mechanics, 45, 1, 1-20 